\title{
Durability Assessment of Concrete Structures in HZM Sea Link Project for Design Life of 120 Years
}

\author{
K. F. Li, Q. W. Li, and Q. M. Zhang \\ Department of Civil Engineering, Tsinghua University \\ Z. H. Fan \\ CCCC 4th Harbor Research Institute \\ L. H. Yang \\ Planning and Design Institute of Water Transportation
}

\begin{abstract}
This article presents the durability assessment of the concrete structures in the ongoing Hong Kong-ZhuhaiMacao (HZM) sea link project for a design service life of 120 years. During the preliminary study phase, the durability design of concrete structures has been performed by a model-based method with a partial factor scheme for chloride-induced corrosion process. On the basis of the actual design options adopted in the detailed design phase, the durability assessment of concrete structures is performed for the achieved durability and reliability levels. For this purpose, the durability assessment retains the same model for chloride-induced corrosion as in the preliminary design phase, and takes into account the actual design options for concrete elements such as concrete surface coating, epoxy-coated steel bars, and stainless steel bars. The probabilistic approach is adopted for the durability assessment to evaluate the reliability levels for the design life of 120 years. Following the same probabilistic analysis, the maintenance scheme of concrete elements is investigated with specified reliability levels for different maintenance strategies.
\end{abstract}

\section{INTRODUCTION}

Probably the largest ongoing civil engineering infrastructure, the project of Hong Kong-ZhuhaiMacau (HZM) links the cities of Zhuhai, Macau and Hong Kong along the China south-eastern coast. It consists of sea bridges of $28.8 \mathrm{~km}$, two artificial islands and an immerged tube tunnel of $6.8 \mathrm{~km}$, with a total investment over 12 billion US dollars. The design life of the project is 120 years (HPDI, 2008). The preliminary study of the project began from 2008 to 2010 , the detailed study phase started from 2010 , and construction works are expected to end between 2015 and 2016.

One of the main technical challenges of the whole project is to ensure the service life of 120 years for the concrete structures in an aggressive marine environment. The project is situated in the southern subtropical marine monsoon region of China. Based on the project hydrological investigation (CCCC, 2009), the annual average temperature is between 22.3 and $23.1^{\circ} \mathrm{C}$. The hydrology data show that the chloride ions $\left(\mathrm{Cl}^{-}\right)$content in sea water at the project site is in the range of $10700-17020 \mathrm{mg} / \mathrm{L}$ and the content of sulfate ions $\left(\mathrm{SO}_{4}{ }^{2-}\right)$ is in the range of 1140 $2260 \mathrm{mg} / \mathrm{L}$. The $\mathrm{pH}$ of sea water is between 6.65 and 8.63. The tide and wave data show that the range of tidal zone, below the splashing zone and above the submerged zone, is relatively narrow.

During the preliminary study phase, the durability design of concrete structures has been performed by the model-based method, with a partial factor scheme for chloride-induced corrosion process. The partial factors are calibrated through full probabilistic approach with a preliminary reliability index $\beta=1.3$. The corresponding durability limit state (DLS) is the corrosion initiation of steel bars. The obtained design results serve as basis for the subsequent detailed design phase. To ensure enough safety margin for durability design, different protection measures are taken in this design phase. In this article, considering these actually taken protection measures, the durability reliability levels for reinforced concrete $(R C)$ elements and prestressed concrete (PC) elements are evaluated through full probabilistic approach and the assessment results also provide a basis for the maintenance planning of the full life cycle of concrete structures.

\section{DURABILITY DESIGN OPTIONS}

From the preliminary design, it was judged that the chloride-induced corrosion dominates the durability design, thus the chloride diffusion coefficient is chosen 
as the material durability parameter for concrete elements. The durability parameters from the structural side include mainly the concrete cover thickness and the crack control. The durability parameters obtained from the preliminary design phase are summarized in Table 1, together with the different exposure conditions for the concrete elements. It is noted that some concrete elements, for example, piers and bearing platforms, can transverse several exposures zones, such as tidal, splashing, and submerged zones. The DLS is chosen as the corrosion initiation of reinforcement steel, noted as (a) in the table. It is also to be noted that since the tidal zone is relatively narrow $(\sim 1.70 \mathrm{~m})$, the durability design and assessment make no further difference for the tidal and splashing zones. In other words, the tidal zone is merged into the splashing zone for the sake of conservative design.

Table 1. Durability design parameters for elements of concrete structures in HZM project.

\begin{tabular}{llcccc}
\hline Element & Exposure & $\begin{array}{c}\text { Design } \\
\text { life } \\
\text { (year) }\end{array}$ & DLS & $\begin{array}{c}\text { Cover } \\
\boldsymbol{x}_{\mathrm{d}}^{\text {nom }} \\
(\mathbf{m m})\end{array}$ & $\begin{array}{c}\mathbf{D}_{\mathrm{cl}} \\
\left(\mathbf{1 0 ^ { - 1 2 }} \mathbf{~ m}^{2} \mathbf{s}\right) / \\
\mathbf{2 8} \text { days }\end{array}$ \\
\hline $\begin{array}{l}\text { Box girder } \\
\text { (exterior) }\end{array}$ & $\begin{array}{l}\text { Salt frog } \\
\text { Splashing }\end{array}$ & 120 & $\begin{array}{c}\text { (a) } \\
\text { (a) }\end{array}$ & $\begin{array}{c}45 \\
80\end{array}$ & $\begin{array}{c}6.0 \\
6.5\end{array}$ \\
\hline $\begin{array}{l}\text { Box girder } \\
\text { (interior) }\end{array}$ & Salt frog & 120 & (a) & 45 & 6.0 \\
\hline $\begin{array}{l}\text { Pier, Pylon } \\
\text { (exterior) }\end{array}$ & Salt frog & 120 & (a) & 50 & 6.5 \\
\hline $\begin{array}{l}\text { Pier } \\
\text { (interior) }\end{array}$ & Salt frog & 120 & (a) & 50 & 6.5 \\
\hline $\begin{array}{l}\text { Bearing } \\
\text { platforms }\end{array}$ & Splashing & 120 & (a) & 85 & 6.5 \\
\hline $\begin{array}{l}\text { Bored hole } \\
\text { pile }\end{array}$ & Immerged & 120 & (a) & 65 & 6.5 \\
\hline $\begin{array}{l}\text { RC facilities } \\
\text { (artificial }\end{array}$ & Splashing & 50 & (a) & 60 & 6.5 \\
islands) & 120 & (a) & 65 & 7.0 \\
\hline $\begin{array}{l}\text { Tunnel tube } \\
\text { (exterior) }\end{array}$ & Splashing & 120 & (a) & 80 & 6.5 \\
\hline $\begin{array}{l}\text { Tunnel tube } \\
\text { (interior) }\end{array}$ & Salt frog & 120 & (a) & 50 & 6.5 \\
\hline
\end{tabular}

In Table 2 are recapitulated the durability protection measures retained in the detailed design phases. These measures include mainly the surface coating for concrete, corrosion inhibitors in concrete, the epoxy resins for reinforcement steel bars, stainless steel bars for severe exposure zones as well as cathodic protection for the composite piles and the reinforcement steel bars in immersed tube tunnel. The parameters given in Table 1 and the protection measures taken in Table 2 constitute the actual basis for durability safety for concrete elements and structures. The cathodic protection for the tube tunnel is designed for all the reinforcement steel bars in the tube segments, but remains at first inactive after construction. The protection is to be activated as the durability failure of steel bars occurs under natural or accidental actions.

Table 2. Protection measures for RC/PC elements of concrete structures in HZM project.

\begin{tabular}{lll}
\hline Element & Exposure & Measures \\
\hline \multirow{2}{*}{ Box girder (exterior) } & Salt frog & Coatings \\
& Splashing & Stainless bar + coating \\
\hline Box girder (interior) & Salt frog & - \\
\hline Pier, Pylon (exterior) & Salt frog & Coatings \\
& Splashing & Stainless bar + coating \\
\hline Pier (interior) & Salt frog & - \\
\hline \multirow{2}{*}{ Bearing platforms } & Splashing & Epoxy-coated bar + coating \\
& Immerged & Surface coating \\
\hline Bored hole pile & Immerged & - \\
\hline RC facilities (islands) & Splashing & Surface coatings \\
\hline Tunnel tube (exterior) & Splashing & Cathodic protection \\
\hline Tunnel tube (interior) & Salt frog & Cathodic protection \\
\hline
\end{tabular}

\section{ASSESSMENT MODEL}

The durability levels of concrete elements are assessed with respect to the chloride-induced corrosion of steel reinforcement bars in RC/PC elements. The assessment model for chloride-induced corrosion is adapted from the widely used analytical model of Fick's second law (DuraCrete, 1998; fib, 2006). With the DLS specified as the corrosion initiation state (a), the design equation can be written as,

$$
G=C_{\mathrm{cr}}-C_{\mathrm{s}}\left[1-\operatorname{erf}\left(\frac{x_{\mathrm{d}}}{\sqrt{D_{\mathrm{cl}} \cdot t_{\mathrm{SL}}}}\right)\right]=0
$$

With $C_{\mathrm{cr}, \mathrm{s}}$ standing for the threshold chloride concentration for steel corrosion and the concrete surface chloride concentration (in mass percentage of binders), $x_{d}$ is the concrete cover thickness $(m), D_{c l}$ is the chloride diffusion coefficient of concrete $\left(\mathrm{m}^{2} / \mathrm{s}\right), t_{\mathrm{sL}}$ is the design service life of structural elements, and erf is the mathematical error function. Usually, the chloride diffusion coefficient, $D_{\mathrm{cl}}$, is assumed to adopt a power function in terms of concrete exposure age $t$,

$$
D_{\mathrm{cl}}(t)=D_{\mathrm{cl}}^{0}\left(\frac{t_{0}}{t}\right)^{n}=D_{\mathrm{cl}}^{0} \eta\left(t_{0}, t\right)
$$

with $n$ as the exponential coefficient for $D_{\mathrm{cl}}$ decrease law and $D_{0}$ the diffusion coefficient for concrete age $t_{0}$. The term $\eta\left(t_{0}, t\right)$ is the aging coefficient of diffusion coefficient. The main mechanism for this decrease is the microstructure evolution due to longterm hydration of binders after concrete hardening (Andrade, Castellote, \& Andrea, 2011). Since it is not rational to assume $D_{c \mid}$ decreases infinitively with exposure age, this decrease law is truncated at $t=30$ years for durability design in HZM project: 


$$
\left.\eta\left(t_{0}, t\right)\right|_{t>30 \text { years }}=\eta\left(t_{0}, t=30 \text { years }\right)
$$

In other words, the coefficient decreases no longer with exposure age after 30 years' exposure. Thus, this models contains five parameters totally: $C_{\mathrm{cr}}, C_{\mathrm{s}}, x_{\mathrm{d}}, D_{0}$, and $n$ (or $\eta$ ), for a given target service life $t_{\mathrm{SL}}$.

Full probabilistic approach is retained to evaluate the durability reliability for concrete elements exposed to different marine zones. Thus, the statistical properties of the above parameters must be specified. The statistical properties of these parameters are regressed from the in situ investigations on the concrete elements of marine harbors during the past 30 years in the region of South-eastern China, as well as the data from Zhanjiang exposure station during the past 20 years. The statistical properties retained in the reliability assessment are given in Table 3.

Equally, the protection measures should be taken into account in the assessment. For concrete surface coatings, the constitutive materials are epoxy resinbased paints and can be applied to the concrete surface under dry or wet condition. The nominal service life of these coatings was reported as 15 years (Bolzoni, Ormellese, \& Brenna, 2011; Zen, 2005), and the service life of coating is conservatively retained as 10 years in the assessment. It is assumed that, on applying surface coatings, the chloride penetration process is simply delayed by 10 years. For stainless steel bars, these bars are used in the RC/PC elements exposed in splashing zones. It is reported that the critical chloride concentration, $C_{c r}$, for stainless steel can be 10-20 times higher than the conventional steel bars (ACl-365 Committee, 2000; Basham, 1999).
In the assessment, the critical chloride concentration is taken as five times $C_{c r}$ of conventional reinforcement steel. For epoxy-resin coated steel bars, literature shows the corrosion resistance of coated bars can be substantially increased as the surface damage of coating is strictly controlled (Basham, 1999). Since no special measures are undertaken to ensure the surface damage of epoxy-resin coatings in the project, it is conservatively assumed that these coatings have no impact on the corrosion process.

\section{RELIABILITY ASSESSMENT}

With the model presented from Equation (1) to Equation (3), parameters in Table 3 and the modeling assumptions for different protection measures, the failure probability of performance function in Equation (1) is evaluated using Monte-Carlo simulation techniques, and the resulted time-dependent failure probability is converted to the reliability index for $t_{\mathrm{SL}}=$ 120 years (Table 4). The appropriate reliability level sufficient for durability of 120 years is itself a topic to be deepened. Without further rigorous discussion on probability basis, the suggested value from fib model code, $\beta=1.5-1.8$ (fib , 2010), is used as a first criterion for durability safety margin.

From the reliability indices in Table 4, some important observations can be obtained. For the elements in atmospheric zone, the reliability index is generally high $(\beta>2.0)$ and the durability safety margin can be regarded as sufficient for a service life of 120 years. For the elements in splashing (tidal) zone, the situation is quite different. For elements with stainless bars the reliability index is quite high $(\beta>5.0)$, and this index is 2.2 for elements (bearing platform) using only epoxy-coated bar

Table 3. Statistical properties for durability parameters in full probabilistic assessment for concrete structures in HZM project.

\begin{tabular}{|c|c|c|c|c|c|}
\hline $\begin{array}{l}\begin{array}{l}\text { Parameter } \\
\text { (distribution) }\end{array} \\
\end{array}$ & Statistical properties & Immerged zone & Tidal zone & $\begin{array}{l}\text { Splashing } \\
\text { zone }\end{array}$ & $\begin{array}{c}\text { Atmospheric } \\
\text { zone }\end{array}$ \\
\hline \multirow{2}{*}{$\begin{array}{l}\text { Surface concentration } \\
\text { (lognormal) }\end{array}$} & Average (\%) & 4.5 & 3.8 & 5.4 & 2.0 \\
\hline & Deviation (\%) & 0.68 & 0.58 & 0.82 & 0.31 \\
\hline \multirow{4}{*}{$\begin{array}{l}\text { Critical concentration } \\
\mathrm{C}_{\mathrm{cr}} \text { (beta) }\end{array}$} & Lower bound $L(\%)$ & 1.0 & 0.45 & 0.45 & - \\
\hline & Upper bound $U(\%)$ & 3.5 & 1.25 & 1.25 & - \\
\hline & Coefficient $\alpha(-)$ & 0.23 & 0.22 & 0.22 & - \\
\hline & Coefficient $\beta(-)$ & 0.33 & 0.36 & 0.36 & - \\
\hline \multirow{2}{*}{$\begin{array}{l}\text { Critical concentration, } \\
C_{\mathrm{cr}} \text { (lognormal) }\end{array}$} & Average (\%) & - & - & - & 0.85 \\
\hline & Deviation (\%) & - & - & - & 0.13 \\
\hline \multirow{2}{*}{$\begin{array}{l}\text { Diffusion coefficient } D_{\mathrm{cl}}{ }^{0} \\
\text { (lognormal) }\end{array}$} & Average $\left(10^{-12} \mathrm{~m}^{2} / \mathrm{s}\right)$ & Design value & Design & Design & Design \\
\hline & Coefficient of variance & 0.2 & 0.2 & 0.2 & 0.2 \\
\hline \multirow{2}{*}{$\begin{array}{l}\text { Exponent coefficient } n \\
\text { (normal) }\end{array}$} & Average (-) & 0.44 & 0.46 & 0.47 & 0.53 \\
\hline & Deviation (-) & 0.028 & 0.029 & 0.029 & 0.079 \\
\hline \multirow{2}{*}{$\begin{array}{l}\text { Concrete cover } x_{d} \\
\text { (normal) }\end{array}$} & Average (mm) & \multicolumn{4}{|c|}{ Design value } \\
\hline & Deviation (mm) & \multicolumn{4}{|c|}{$\begin{array}{l}5.3 \text { (cast-in-place) } \\
3.0 \text { (prefabricated) }\end{array}$} \\
\hline
\end{tabular}


and surface coating. For the elements in the immerged zone, the reliability index $\beta=2.5$. Using $\beta=1.5-1.8$ as criterion, these elements can be considered having enough durability margin for a service life of 120 years.

Table 4. Reliability index from full probabilistic assessment of durability of concrete structures in HZM for a service life of 120 years.

\begin{tabular}{llc}
\hline Element & Exposure & Reliability index $\beta$ \\
\hline \multirow{2}{*}{ Box girder (exterior) } & Salt frog & 2.4 \\
\cline { 2 - 3 } & Splashing & $>5.0$ \\
\hline Box girder (interior) & Salt frog & 2.4 \\
\hline \multirow{2}{*}{ Pier, Pylon (exterior) } & Salt frog & 4.0 \\
\cline { 2 - 3 } & Splashing & $>5.0$ \\
\hline \multirow{2}{*}{ Pier (interior) } & Salt frog & 3.3 \\
\cline { 2 - 3 } Bearing platforms & Splashing & 0.81 \\
\hline \multirow{2}{*}{ Bored hole pile } & Splashing & 2.2 \\
\hline Tunnel tube (exterior) & Immerged & 2.5 \\
\hline \multirow{2}{*}{ Tunnel tube (interior) } & Splashing & 2.5 \\
\cline { 2 - 3 } & Salt frog & 1.57 \\
\hline
\end{tabular}

In addition, two accidental scenarios are considered in the simulations for pier and tunnel tube elements: the intrados of these elements, under normal working conditions, are considered to be exposed to marine air, and so an atmospheric exposure is retained for the intrados of these elements; however, under accidental scenarios, sea water can penetrate into the intrados of these elements by leaking. Under this unfavorable scenario, the intrados can be exposed to drying-wetting actions from sea water, thus equivalent to splashing zone.

The reliability indices obtained for these accidental/ unfavorable exposure conditions do raise some concern. For prefabricated piers, these elements are void and the intrados can come into contact with sea water as the joint between prefabricated segments fails. Under this accidental scenario, the durability index can drop to $\beta=0.86\left(p_{\mathrm{f}}=19 \%\right)$ at the end of 120 years (Table 4 ). For the intrados of tube tunnel segment, the durability index falls into negative values $(\beta=-0.02)$ as sea water leaks in and comes into contact with concrete surface. The observations will help the maintenance planning of the concrete elements during their service lives.

\section{PRELIMINARY MAINTENANCE PLANNING}

From the obtained time-dependent reliability, a preliminary maintenance planning can be formulated. First, probability thresholds should be defined for the maintenance actions, that is, under what level of failure probability the maintenance should be considered necessary. According to the state-of-the-art knowledge on maintenance strategy, the preventive, necessary, and mandatory maintenance strategies correspond, roughly, to the failure probability levels of 2, 5, and $20 \%$ (Chiu, Noguchi, \& Kanematsu, 2010; Yang, Li, \& Pang, 2013) with respect to DLS (a). Using these probabilities as criteria, the preliminary maintenance planning can be formulated on the basis of the obtained reliability indices.

For RC/PC elements in atmospheric zone in bridges, the time-dependent failure probability is shown in Figure 1 for cast-in-place elements and in Figure 2 for prefabricated elements. On Figures 1 and 2, the two options are presented for concrete elements with and without surface coatings. Since the surface coating is considered to be valid during 10 years, the failure probability for elements with coatings can be read from the no-coating curves at $t_{\mathrm{SL}}=110$ years. Compared to the cast-in-place elements, the prefabricated elements have less construction error on the concrete cover thickness. From Figures 1 and 2 , one can see that $p_{\mathrm{f}}$ for atmospheric zone elements is rather low, $<0.3 \%(\beta>2.7)$ for cast-in-place elements and $<1 \%(\beta>2.3)$ for prefabricated elements. Thus, these elements can be considered being exempted from maintenance during a service life of 120 years.

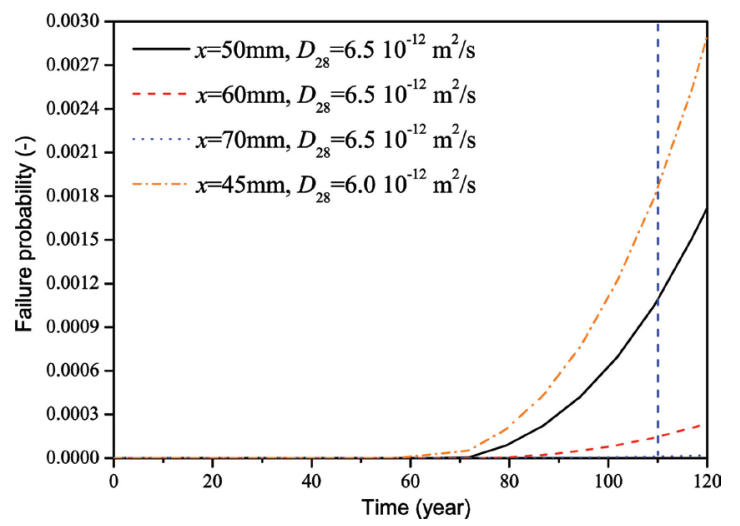

Figure 1. Failure probability for RC/PC elements (cast-in-place) of bridge structures in atmospheric zone.

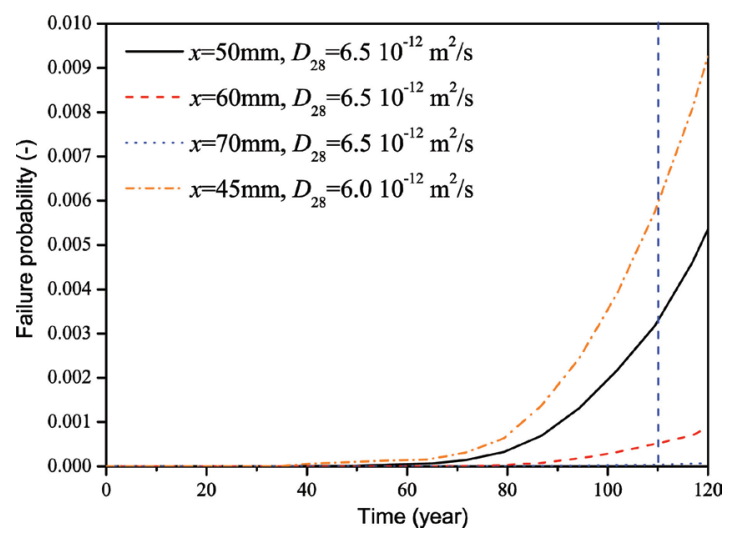

Figure 2. Failure probability for RC/PC elements (prefabricated) of bridge structures in atmospheric zone.

For RC/PC elements in splashing/tidal zone in bridges, the time-dependent failure probability is shown in 
Figure 3. The two options, with and without concrete surface coating, are presented on the figure, and the $p_{\mathrm{f}}$ with surface coating is read from the curves without coating at $t_{\mathrm{sL}}=110$ years. Both cast-in-place and prefabricated elements are considered in Figure 3. With the durability parameters in Table 1 and the protected measures in Table 2, the RC/PC elements in splashing/tidal zone do not need maintenance during the service life of 120 years under normal working conditions. However, concern is raised for the intrados of prefabricated piers: if salty water's penetration is considered as a design scenario, some local strengthening measures should be taken.

For $\mathrm{RC} / \mathrm{PC}$ elements in submerged zone (bearing platform, piles) in bridges, the final $p_{\mathrm{f}}$ is approaching $4 \%$ for the case of cover thickness $60 \mathrm{~mm}$ without surface coating (Figure 4). This probability is situated between the preventive and necessary maintenance criteria. Considering the fact that the reinforcement steel (prefabricated bearing platforms) in this case has the protection of epoxy-resin coatings (Table 2), these elements can be considered to be exempted from maintenance during the service life of 120 years. However, a close inspection program should be set up for these elements to get the real durability performance.

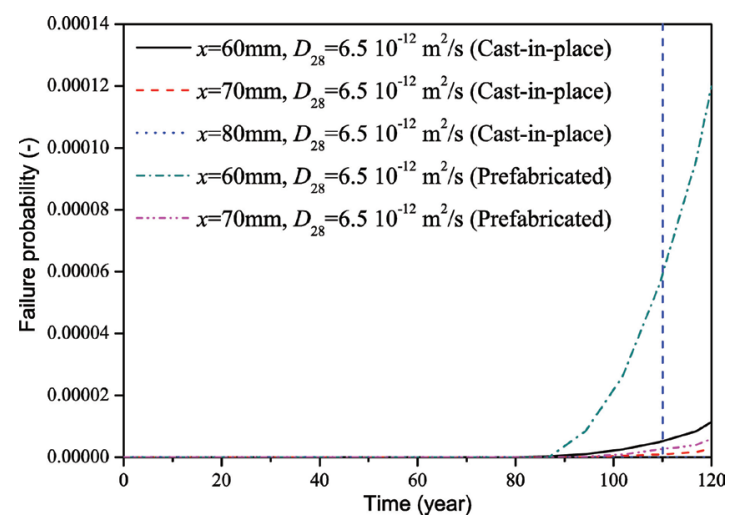

Figure 3. Failure probability for RC/PC elements (cast-in-place and prefabricated) of bridge structures in splashing zone.

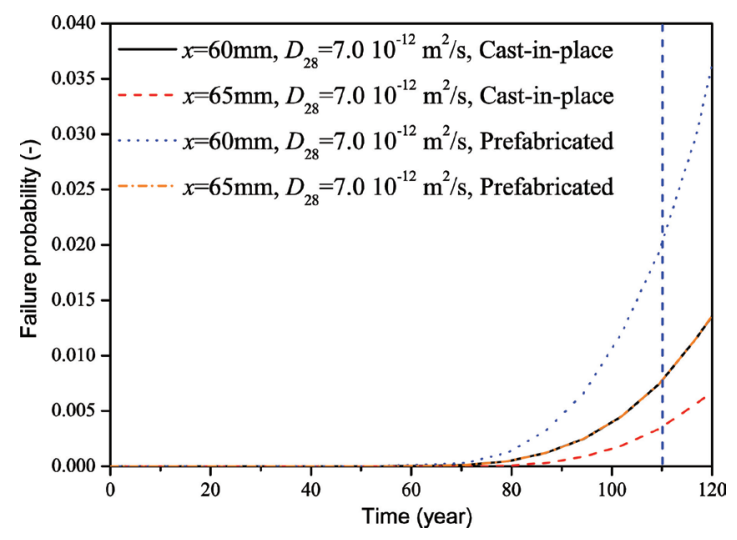

Figure 4. Failure probability for RC/PC elements (cast-in-place and prefabricated) of bridge structures in immerged zone.
For RC elements in the immersed tube tunnel, the failure probability is shown in Figure 5. In Figure 5, two scenarios are considered for the intrados: without sea water leaking and with sea water leaking. As the internal side is free from sea water leaking, that is, the water-tight joints between segments ensure no failure, the internal side is considered exposed to marine air (atmospheric zone). As sea water leaking does happen, a splashing exposure is considered for the internal surface. From Figure 5, one can see that, for the external side, the $p_{\mathrm{f}}$ at 120 years approaches the necessary maintenance criterion (5\%), thus some additional measures are necessary. In Table 2, the cathodic protection has been planned for the reinforcement steel cages in the tunnel segments. This protection will be activated at the moment of durability failure. For the internal sides, the $p_{f}$ is very small for no leaking case $(\beta>2.6)$, while this failure probability can raise rapidly to huge values under leaking case.

Using the data in Figure 5 , one can predict the activated time for the cathodic protection. For external side, this activation time is estimated as 100 years using $p_{\mathrm{f}}=2 \%$ as maintenance threshold. For internal side, this time is estimated as 55 years after the sea water leaking. Certainly, this information for intrados of tube segment should be interpreted with precaution: normally the sea water leaking, even occurred, is a rather local phenomenon, and involves only some local area of intrados. So the efficient counter measure for this eventual failure mode is to strengthen the water leaking monitoring and the water tightness of joints between segments.

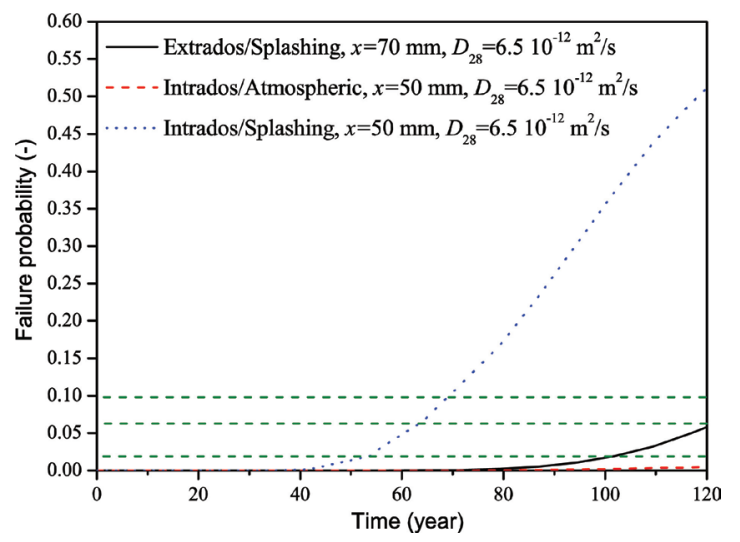

Figure 5. Failure probability for RC elements in immersed tube tunnel.

\section{CONCLUSIONS}

(1) Full probabilistic approach is used to evaluate the durability reliability levels for the concrete structures of the ongoing HZM sea link project. 
The dominating durability process is identified as the chloride-induced corrosion process. The assessment model is the widely used Fick's diffusion model and the statistical properties of the relevant parameters are regressed from the in-place investigation data and data from exposure station. The DLS is chosen as the corrosion initiation of reinforcement steel. The time-dependent failure probability is solved through Monte-Carlo simulation techniques.

(2) From the obtained results, the RC/PC elements in bridge structures have relatively low failure probability, the achieved reliability indices $\beta>2.0$, and the maintenance is not needed for service life of 120 years for most elements. The only exception is the prefabricated bearing platform, which has a final $p_{f}$ approaching $4 \%$, necessitating a planned monitoring/inspection program during the service life. The reliability index for the intrados of void prefabricated piers is very low $(\beta=0.86)$ under an accidental scenario as the sea water penetrates into the void through the joint. Thus, the water tightness of joint between segments of prefabricated piers is a key point for in-place quality control.

(3) For RC elements in tunnel, the segments have different reliability levels for external and internal sides. To keep the reliability index $>1.8$ at the end of service life of 120 years for the extrados of tunnel tube, the cathodic protection needs to be activated during the service life, at $t_{\mathrm{SL}}=100$ years, using $p_{\mathrm{f}}=2 \%$ as criterion. The situation of tube intrados is different according to the water tightness of tunnel wall and tunnel joints: as a perfect water tightness is ensured the reliability index of intrados is well $>1.8$ and no additional protection measures are needed; as the leaking of sea water occurs, the reliability index can drop rapidly to a very low level, that is,. 55 years below $\beta=2.0$. This observation makes necessary a detailed planning of water tightness monitoring for the intrados of tunnel tube during the service life.

\section{REFERENCES}

ACl-365 Committee. (2000). Computer program for predicting the service life and life-cycle costs of reinforced concrete exposed to chloride.

Andrade, C., Castellote, M., \& Andrea, R. (2011). Measurement of ageing effect on chloride diffusion coefficients in cementitious materials. Journal of Nuclear Materials, 412, 209-216.

Basham, K. (1999). Choices in corrosion-resistant rebar. Concrete and Construction, C99J027, 4.

Bolzoni, F., Ormellese, M., \& Brenna, A. (2011). Efficiency of concrete coatings on chloride-induced corrosion of reinforced concrete structures. In NACE-International Corrosion Conference Series, 2011, NACE International - Corrosion 2011 Conference and Expo. 2011, Houston.

CCCC. (2009). Durability Assessment and Concrete Experimental Study for Preliminary Design of HZM Project. Guangzhou, China: HZM Bridge Administration.

Chiu, C. K., Noguchi, T., \& Kanematsu, M. (2010). Effects of maintenance strategies on the lifecycle performance and cost of a deteriorating $\mathrm{RC}$ building with high-seismic hazard. Journal of Advanced Concrete Technology, 8(2), 157-170.

DuraCrete. (1998). Probabilistic performance based durability design: Modeling of degradation. DuraCrete Project Document BE95-1347/R4-5. The Netherlands.

fib. (2006). Model code for service life design. Bulletin 34. Lausanne, Switzerland: Fédération International du Béton.

fib. (2010). Model Code 2010. First complete draft. Bulletin 55/56. Lausanne, Switzerland: Fédération International du Béton.

HPDI. (2008). The Feasibility Study Report on Hong Kong-Zhuhai-Macau Sea Link Project. Beijing, China: HZM Bridge Administration.

Yang, L. H., Li, K. F., \& Pang, X. Y. (2013). Design and optimization of maintenance strategies for a long life-span port project. Materials and Structures, 46(1-2), 161-172.

Zen, K. (2005). Corrosion and life cycle management of port structures. Corrosion Science, 47(10), 2353-2360. 